\title{
Association between the PPAR $\gamma$ Pro12Ala polymorphism and risk of gestational diabetes mellitus: a meta-analysis
}

\author{
H.L. Shuai ${ }^{1 *}$, X.Z. Lin ${ }^{1 *}$, D.L. Chen ${ }^{1}$, P. Li ${ }^{2}$ and X. Luo ${ }^{1}$ \\ ${ }^{1}$ Department of Gynecology \& Obstetrics, \\ The First Affiliated Hospital of Jinan University, Guangzhou, China \\ ${ }^{2}$ Department of Nursing Science, School of Medicine, Jinan University, \\ Guangzhou, China \\ *These authors contributed equally to this study. \\ Corresponding author: P. Li \\ E-mail: pingli201509@sina.com
}

Genet. Mol. Res. 15 (4): gmr15047682

Received January 9, 2016

Accepted June 9, 2016

Published November 3, 2016

DOI http://dx.doi.org/10.4238/gmr15047682

Copyright (C) 2016 The Authors. This is an open-access article distributed under the terms of the Creative Commons Attribution ShareAlike (CC BY-SA) 4.0 License.

\begin{abstract}
The relationship between the Pro12Ala polymorphism of PPAR $\gamma$ and the risk of gestational diabetes mellitus remains unresolved. Here, we attempted to resolve this inconsistency. Case-control studies pertaining to the effect of the Pro12Ala polymorphism in the PPAR $\gamma$ protein and risk of gestational diabetes mellitus were extracted from the HuGE, PubMed, Web of Science, CNKI, and SinoMed databases after an extensive literature search. The studies were statistically analyzed using STATA (v.12.0) software. Twelve case-control studies composed of 2968 GDM cases and 5576 controls that fulfilled the inclusion criteria were included in this meta-analysis. We identified no significant relation between the Pro12Ala polymorphism of PPAR- $\gamma$ and risk of GDM, when analyzed by the allele [G vs C: odds ratio
\end{abstract}


$(\mathrm{OR})=0.85 ; 95 \%$ confidence interval $(\mathrm{CI}): 0.71-1.01]$ and dominant $(\mathrm{CG}+\mathrm{GG}$ vs CC: $\mathrm{OR}=0.86$; 95\% CI: 0.72-1.03) models. Subgroup analysis by ethnicity revealed that East Asian and Middle Eastern females expressing the A allele showed reduced susceptibility to GDM. Additionally, we observed significant differences between the East Asian, Middle Eastern, and Caucasian females $(\mathrm{P}=0.008)$ with respect to GDM susceptibility. The results of this meta-analysis indicated the influence of ethnicity in determining GDM susceptibility, in the presence of a Pro12Ala polymorphism in PPAR $\gamma$.

Key words: Pro12Ala polymorphism; PPARs; Gestational diabetes mellitus; Meta-analysis

\section{INTRODUCTION}

Gestational diabetes mellitus (GDM), a common pregnancy complication, refers to the conversion of normal glycometabolism or potential glucose intolerance before pregnancy to abnormal glycometabolism during the gestation period. This type of endocrine disorder is generally resolved immediately after delivery (Reece et al., 2009). However, GDM poses a growing health concern in both mothers and offsprings (Zhang et al., 2013). Inadequate glycemic control causes early and long-term complications (Yan and Yang, 2014): pregnant women may experience abnormal metabolism, type 2 diabetes mellitus, and even abortion and gestational hypertension. Women afflicted with GDM during a prior pregnancy also face a high risk of recurrence during subsequent pregnancies (Bottalico, 2007). The average frequency of recurrent GDM is 48\% (Schwartz et al., 2015), ranging from 30 to $88 \%$ (Bottalico, 2007; Kim et al., 2007; Verier-Mine, 2010). On the other hand, the higher concentrations of glucose in the mother will result in excess insulin production in the fetus, which may cause macrosomia (Gojnic et al., 2012), fetal growth restriction (Barbour, 2014), as well as respiratory distress syndrome, cardiomyopathy, and hypoglycemia in neonates (Jones, 2001). Recent highprofile studies have also highlighted the yearly increase in GDM-related morbidity: the WHO estimated that more than 300 million women would be affected by this disorder (WHO, 2009). When excluding factors such as advanced age and obesity, genetics has been shown to contribute to the occurrence of GDM; that is, the occurrence of GDM shows genetic susceptibility (Watanabe, 2011) and a familial tendency (Solomon et al., 1997).

Peroxisome proliferator-activated receptors (PPARs) are ligand-inducible transcription factors belonging to a subfamily of the nuclear receptor superfamily (Guri et al., 2006). PPARs play a key role in regulating the cell differentiation and growth, glucose metabolism, and lipid metabolism, especially in the maintenance of metabolic homeostasis (Monsalve et al., 2013), similar to the functions of some steroid receptors. Three subtypes of PPARs have been identified so far: PPAR $\alpha, \operatorname{PPAR} \beta / \delta$, and PPAR $\gamma$. PPAR $\gamma$ is associated with the induction of differentiation and proliferation in adipocytes (Tontonoz and Spiegelman, 2008), as well as simultaneous modulation of insulin sensitivity. Moreover, many genes involved in adipocyte lipid storage and glucose homeostasis are directly activated or modulated by PPAR $\gamma$ (Bou et al., 2014; Christodoulides and Vidal-Puig, 2010).

Previous meta-analyses have indicated that the Pro12Ala polymorphism in PPAR $\gamma$

Genetics and Molecular Research 15 (4): gmr15047682 
may function as a protective factor for the development of GDM (Wang et al., 2013; Zhang et al., 2013). However, the results of these studies are inconsistent and remain to be further validated. These inconsistent results were verified in this meta-analysis comprising 12 casecontrol studies, where the relationship between the PPAR $\gamma$ Pro12Ala polymorphism and the risk of GDM was clarified.

\section{MATERIAL AND METHODS}

\section{Search strategy}

The eligible studies were electronically retrieved from the PubMed, HuGE Navigator, Web of Science SCI, China National Knowledge Infrastructure (CNKI), and SinoMed databases using various combinations of the following keywords and medical subject headings: "gestational diabetes mellitus", "gene", "genetics", "variant", "polymorphism", "SNP", "peroxisome proliferator activated receptor", and "PPAR $\gamma$ ". The search was limited to human studies; however, no language limitations were set.

\section{Selection and exclusion criteria}

The candidate studies were based on the following inclusion criteria: a) published papers reporting the association between PPAR $\gamma$ and risk of GDM, b) case-control or cohort studies, and c) cases meeting the GDM diagnostic criteria. Additionally, the numbers of case and control groups reported for each genotype, or other data such as the genotyping method used should allow for the calculation of the Odd's ratios (ORs) and their corresponding 95\% confidence intervals (CIs). Moreover, the genotype of each control group should conform to the Hardy-Weinberg equilibrium (HWE) status (determined by a chi-squared test). All included studies were also assessed by the Newcastle-Ottawa Scale (NOS) quality score system. A study was rated to be of high quality when the NOS scores were $>6$ (out of a total of 9 stars) (Stang, 2010). Studies were excluded when the study design was not that of a casecontrol study; additionally, duplicates, and studies that did not report the requisite data were also excluded.

\section{Data extraction}

The extracted studies were carefully and independently investigated by two examiners; the titles were first examined, followed by the full text of the article. Inconsistencies were resolved by adjudication and discussion, and by intervention of a third investigator. The author of a specific study was contacted when required. The following data was extracted from the study: surname of the first author, year of publication, details of the sample populations (e.g. mean age, ethnic/racial composition, and body mass index), overall sample size, genotyping method, and the frequency of genotypes.

\section{Statistical analysis and risk of bias-assessments}

The Odds' ratios (ORs) and their corresponding 95\% CI values were used as effective measures to assess the association between the Pro12Ala polymorphism of PPAR $\gamma$ and GDM 
in dominant $\left(\mathrm{CG}+\mathrm{GG} v_{s} \mathrm{CC}\right)$ and allele $\left(\mathrm{G} v_{s} \mathrm{C}\right)$ models. The heterogeneity between studies was calculated using the Cochran Q statistic (Jackson, 2013). The Higgins and Thompson $\mathrm{I}^{2}$ statistic was also used as a measure of the heterogeneity among studies: $\mathrm{P}<0.05$ or $I^{2}>$ $50 \%$ suggested the existence of significant heterogeneity among the included studies. The pooled ORs were estimated using the Mantel Haenszel fixed effect model (FEM) and the Der Simonian Laird random effect model (REM). However, in this meta-analysis, the REM was used in pre-specified stratified analyses and to investigate the possible associations between the ethnicity subgroups and the genotyping method. Possible publication bias was detected using the Begg and Egger tests. All statistical analyses were performed using STATA v.12.0 (Stata Corporation, College Station, TX, USA). All P values were two-sided.

\section{RESULTS}

\section{Search outcomes}

Twelve case-control studies, comprising 2968 GDM patients and 5576 controls, were selected from a total of 192 papers by a thorough review of the abstract and full text of the articles (Figure 1). The included literature was published between 2004 and 2014; the primary sample populations analyzed in the studies were East Asians (7 studies), Caucasians (5), and Middle Eastern (2). The frequency of allele Ala in GDM patients and controls was obtained. We observed an association between GDM and the Pro12Ala polymorphism in 2 studies. The two main genotyping methods applied were restriction fragment length polymorphism (RFLP) and TaqMan. The detailed characteristics and methodological quality of the studies included in this meta-analysis are summarized in Table 1.

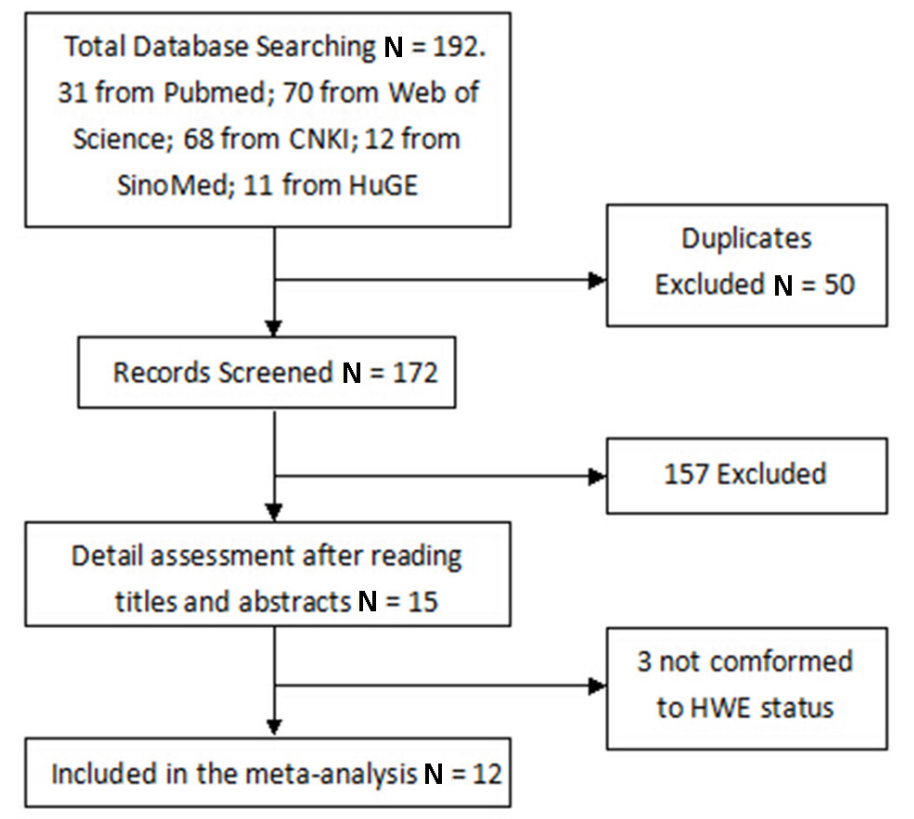

Figure 1. Flow chart of relative studies.

Genetics and Molecular Research 15 (4): gmr15047682 
Table 1. Characteristics of included studies.

\begin{tabular}{|c|c|c|c|c|c|c|c|c|c|c|c|c|c|}
\hline \multirow[t]{2}{*}{ Literature } & \multirow[t]{2}{*}{ Year } & \multirow[t]{2}{*}{ Country } & \multirow[t]{2}{*}{ Ethnicity } & \multirow[t]{2}{*}{$\begin{array}{l}\text { Mean age of } \\
\text { case/control }\end{array}$} & \multirow[t]{2}{*}{$\begin{array}{c}\text { Genotyping } \\
\text { method }\end{array}$} & \multirow[t]{2}{*}{$\begin{array}{l}\text { Mean BMI of } \\
\text { case/control }\end{array}$} & \multirow{2}{*}{$\begin{array}{c}\text { Total } \\
\text { numbers of } \\
\text { case/control }\end{array}$} & \multicolumn{2}{|c|}{$\begin{array}{l}\text { Genotypes } \\
\mathrm{CC} / \mathrm{CG} / \mathrm{GG}\end{array}$} & \multicolumn{2}{|c|}{$\begin{array}{c}\text { Allele } \\
\mathrm{C} / \mathrm{G}\end{array}$} & \multirow[t]{2}{*}{$\begin{array}{l}\text { P for } \\
\text { HWE }\end{array}$} & \multirow[t]{2}{*}{$\begin{array}{l}\text { Scores of } \\
\text { STREGA }\end{array}$} \\
\hline & & & & & & & & Case & Control & Case & Control & & \\
\hline $\begin{array}{l}\text { Yan } \\
\end{array}$ & 2014 & China & East Asian & $30.7 / 28.9$ & RFLP & NA/NA & $156 / 180$ & $144 / 12 / 0$ & $153 / 24 / 3$ & $300 / 12$ & $332 / 30$ & 0.0877 & 6 \\
\hline $\mathrm{Li}$ & 2014 & China & East Asian & & RFL & & $72 / 78$ & $65 / 7 / 0$ & $67 / 11 / 0$ & $137 / 7$ & $135 / 11$ & & 5 \\
\hline Chon & 2013 & & & & & & & & & $183 / 5$ & & & 6 \\
\hline $\mathrm{Du}$ & 2012 & & & & & & & & & & & 0.4288 & 6 \\
\hline Pappa & 2011 & Gree & & & & & & & & & & & 6 \\
\hline Cheng & 2010 & Chi & E & & & & & & & & & 0.5. & 6 \\
\hline Cho & 2009 & Korea & st As & & Taq1 & & & & $567 /$ & 165 & 1197 & 0.8589 & 6 \\
\hline Lauenborg & 2008 & Denmar & Caucasian & & TaqMan & 28.97 & $276 /$ & 201 & $1790 / 542 / 51$ & & $4122 / 644$ & 0.5236 & 6 \\
\hline Shaat & 2007 & Switzerla & Caucasi & & TaqMan & & $637 / 1232$ & $468 / 158 / 11$ & $918 / 298 / 16$ & $1088 / 180$ & $2134 / 330$ & 0.1341 & 6 \\
\hline Shaat & 2004 & Switzerland & Caucasian/Middle Eastern & $32.3 / \mathrm{NA}$ & RFLP & $30.1 / \mathrm{NA}$ & $500 / 550$ & $377 / 120 / 3$ & $423 / 120 / 7$ & $874 / 966$ & $126 / 134$ & 0.6433 & 6 \\
\hline Tok & 2006 & Turkey & Middle Eastern & $33.5 / 31.6$ & RFLP & $26.6 / 23.0$ & $100 / 62$ & $84 / 16 / 0$ & $50 / 12 / 0$ & $112 / 12$ & $184 / 16$ & 0.3845 & 6 \\
\hline
\end{tabular}

\section{Meta-analysis results}

Both the allele and dominant models showed no significant relationship between the Pro12Ala polymorphism in PPAR $-\gamma$ and the risk of GDM (allele model; $\mathrm{G} v s \mathrm{C}: \mathrm{OR}=0.85,95 \%$ CI: 0.71-1.01; dominant model; $\mathrm{CG}+\mathrm{GG} v \mathrm{CC}: \mathrm{OR}=0.86,95 \% \mathrm{CI}: 0.72-1.03)$. East Asian and Middle Eastern women expressing the A allele were less susceptible to GDM, compared to Caucasian women expressing the $\mathrm{G}$ allele. We observed significant differences among the three ethnic populations $(\mathrm{P}=0.008)$, indicating the influence ethnicity on GDM susceptibility. However, the statistical power might be influenced by the small sample size. Similarly, the subtype analysis based on the genotyping method revealed significant differences between the two methods used: TaqMan was found to be more sensitive to GDM (G $v s \mathrm{C}: \mathrm{OR}=0.97,95 \%$ CI: 0.86-1.10; $\mathrm{CG}+\mathrm{GG}$ vs CC: $\mathrm{OR}=0.98,95 \% \mathrm{CI}: 0.85-1.12$ ).

\section{Publication bias}

The Begger's funnel plots and the Egger test revealed no obvious asymmetry and publication bias among the included studies.

\section{DISCUSSION}

PPAR- $\gamma$, a steroid hormone receptor, is highly expressed in adipose tissues and immunocytes, and plays a critical role in the modulation of the intercellular signaling pathway of insulin (Soares et al., 2013). In addition to controlling adipocyte differentiation, it is the master regulator of lipid metabolism through leptin and tumor necrosis factor (Chawla et al., 2006). The $(\mathrm{C} \rightarrow \mathrm{G})$ missense mutation in exon 2 of codon 12, which changes proline to alanine, is the most common mutation occurring in PPAR- $\gamma$ (Franks et al., 2007). The Pro12Ala polymorphism results in a functional variant of PPAR- $\gamma$, which affects the insulin sensitivity (Campbell, 2005). The activity of this ligand-dependent amino terminal can be enhanced through phosphorylation by insulin (Yen et al., 1997), which indicates the association between the Pro12Ala polymorphism and insulin.

In this study, we obtained no evidence of an association between the Pro12Ala polymorphism in PPAR- $\gamma$ and susceptibility to GDM, which was consistent with the results of previous studies (Wang et al., 2013). Conversely, other studies have reported that the expression of the allele Ala decreased the incidence of GDM (Altshuler et al., 2000). On a fundamental level, however, the basis of a meta-analysis is to obtain a relative measurement of observation to support or deny certain assumptions, without being directly combined 
with the research findings. The mismatch between cases and controls indicates a source of the deviation, especially when no large-scale prospective controlled studies are available. Therefore, multiple factors, such as ethnicity, sample size, relative clinical parameters, and research methods could be responsible for these inconsistencies in the results. Multiple factors contribute to the risk of GDM, including interactions between the genetic makeup of an individual and the environment. Allele Ala plays a protective role in preventing GDM; however, this positive effect might be opposite in a person with GDM due to his incident cardiovascular complications and $\beta$ cell damage.

A clinical antenatal survey of the frequency of GDM in more than eleven thousand women from various countries indicated that Asian women are much more susceptible to GDM than those from Europe (Dornhorst et al., 1992). Similar results were obtained by other researchers (Chawla et al., 2006; Carolan, 2013). In this study, we observed a significance difference in GDM incidence between the three racial subgroups; however, this difference was not associated with the Pro12Ala polymorphism, which was inconsistent with the results of some previous epidemiology studies. Notwithstanding the limitations of our meta-analysis, we have determined that the Pro12Ala polymorphism in PPAR $\gamma$ plays a small (or no) role in the occurrence and development of GDM. However, stricter analyses with larger sample sizes, and conducted at multiple centers, will be needed to validate our results.

\section{Conflicts of interest}

The authors declare no conflict of interest.

\section{ACKNOWLEDGMENTS}

ResearchsupportedbytheGuangdongNaturalScienceFoundation(\#2014A030310098) and the Guangdong Medical Scientific Research Foundation (\#A2014376).

\section{REFERENCES}

Altshuler D, Hirschhorn JN, Klannemark M, Lindgren CM, et al. (2000). The common PPARgamma Pro12Ala polymorphism is associated with decreased risk of type 2 diabetes. Nat. Genet. 26: 76-80. http://dx.doi.org/10.1038/79216

Barbour LA (2014). Unresolved controversies in gestational diabetes: implications on maternal and infant health. Curr. Opin. Endocrinol. Diabetes Obes. 21: 264-270. http://dx.doi.org/10.1097/MED.0000000000000080

Bottalico JN (2007). Recurrent gestational diabetes: risk factors, diagnosis, management, and implications. Semin. Perinatol. 31: 176-184. http://dx.doi.org/10.1053/j.semperi.2007.03.006

Bou M, Todorčević M, Rodríguez J, Capilla E, et al. (2014). Interplay of adiponectin, TNF $\alpha$ and insulin on gene expression, glucose uptake and PPAR $\gamma$, AKT and TOR pathways in rainbow trout cultured adipocytes. Gen. Comp. Endocrinol. 205: 218-225. http://dx.doi.org/10.1016/j.ygcen.2014.05.005

Campbell IW (2005). The clinical significance of PPAR gamma agonism. Curr. Mol. Med. 5: 349-363. http://dx.doi. org $/ 10.2174 / 1566524053766068$

Carolan M (2013). Gestational diabetes mellitus among women born in South East Asia: a review of the evidence. Midwifery 29: 1019-1026. http://dx.doi.org/10.1016/j.midw.2012.09.003

Chawla A, Amundsen AL, Hanssen KF and Iversen PO (2006). [Gestational diabetes in women from South Asia]. Tidsskr. Nor. Laegeforen. 126: 1041-1043.

Christodoulides C and Vidal-Puig A (2010). PPARs and adipocyte function. Mol. Cell. Endocrinol. 318: 61-68. http:// dx.doi.org/10.1016/j.mce.2009.09.014

Dornhorst A, Paterson CM, Nicholls JS, Wadsworth J, et al. (1992). High prevalence of gestational diabetes in women from ethnic minority groups. Diabet. Med. 9: 820-825. http://dx.doi.org/10.1111/j.1464-5491.1992.tb01900.x

Genetics and Molecular Research 15 (4): gmr15047682 
Gojnic M, Stefanovic T, Perovic M, Arsic B, et al. (2012). Prediction of fetal macrosomia with ultrasound parameters and maternal glycemic controls in gestational diabetes mellitus. Clin. Exp. Obstet. Gynecol. 39: 512-515.

Guri AJ, Hontecillas R and Bassaganya-Riera J (2006). Peroxisome proliferator-activated receptors: bridging metabolic syndrome with molecular nutrition. Clin. Nutr. 25: 871-885. http://dx.doi.org/10.1016/j.clnu.2006.08.006

Franks PW, Jablonski KA, Delahanty L, Hanson RL, et al.; Diabetes Prevention Program Research Group (2007). The Pro12Ala variant at the peroxisome proliferator-activated receptor gamma gene and change in obesity-related traits in the Diabetes Prevention Program. Diabetologia 50: 2451-2460. http://dx.doi.org/10.1007/s00125-007-0826-6

Jackson D (2013). Confidence intervals for the between-study variance in random effects meta-analysis using generalized Cochran heterogeneity statistics. Res. Synth. Methods 4: 220-229.

Jones CW (2001). Gestational diabetes and its impact on the neonate. Neonatal Netw. 20: 17-23. http://dx.doi. org/10.1891/0730-0832.20.6.17

Kim C, Berger DK and Chamany S (2007). Recurrence of gestational diabetes mellitus: a systematic review. Diabetes Care 30: 1314-1319. http://dx.doi.org/10.2337/dc06-2517

Monsalve FA, Pyarasani RD, Delgado-Lopez F and Moore-Carrasco R (2013). Peroxisome proliferator-activated receptor targets for the treatment of metabolic diseases. Mediators Inflamm. 2013: 549627. http://dx.doi. org/10.1155/2013/549627

Reece EA, Leguizamón G and Wiznitzer A (2009). Gestational diabetes: the need for a common ground. Lancet 373: 1789-1797. http://dx.doi.org/10.1016/S0140-6736(09)60515-8

Schwartz N, Nachum Z and Green MS (2015). The prevalence of gestational diabetes mellitus recurrence--effect of ethnicity and parity: a metaanalysis. Am. J. Obstet. Gynecol. 213: 310-317. http://dx.doi.org/10.1016/j.ajog.2015.03.011

Soares FL, de Oliveira Matoso R, Teixeira LG, Menezes Z, et al. (2013). Gluten-free diet reduces adiposity, inflammation and insulin resistance associated with the induction of PPAR-alpha and PPAR-gamma expression. J. Nutr. Biochem. 24: 1105-1111. http://dx.doi.org/10.1016/j.jnutbio.2012.08.009

Solomon CG, Willett WC, Carey VJ, Rich-Edwards J, et al. (1997). A prospective study of pregravid determinants of gestational diabetes mellitus. JAMA 278: 1078-1083. http://dx.doi.org/10.1001/jama.1997.03550130052036

Stang A (2010). Critical evaluation of the Newcastle-Ottawa scale for the assessment of the quality of nonrandomized studies in meta-analyses. Eur. J. Epidemiol. 25: 603-605. http://dx.doi.org/10.1007/s10654-010-9491-z

Tontonoz P and Spiegelman BM (2008). Fat and beyond: the diverse biology of PPARgamma. Annu. Rev. Biochem. 77: 289-312. http://dx.doi.org/10.1146/annurev.biochem.77.061307.091829

Verier-Mine O (2010). Outcomes in women with a history of gestational diabetes. Screening and prevention of type 2 diabetes. Literature review. Diabetes Metab. 36: 595-616. http://dx.doi.org/10.1016/j.diabet.2010.11.011

Wang C, Li X, Huang Z and Qian J (2013). Quantitative assessment of the influence of PPARG P12A polymorphism on gestational diabetes mellitus risk. Mol. Biol. Rep. 40: 811-817. http://dx.doi.org/10.1007/s11033-012-2119-5

Watanabe RM (2011). Inherited destiny? Genetics and gestational diabetes mellitus. Genome Med. 3: 18. http://dx.doi. org/10.1186/gm232

WHO (2009). WHO Diabetes Program Country and Regional Data. Available at [http://www.who.int/diabetes/facts/ world_figures/en/]. Accessed January 8, 2009.

Yan J and Yang H (2014). Gestational diabetes in China: challenges and coping strategies. Lancet Diabetes Endocrinol. 2: 930-931. http://dx.doi.org/10.1016/S2213-8587(14)70154-8

Yen CJ, Beamer BA, Negri C, Silver K, et al. (1997). Molecular scanning of the human peroxisome proliferator activated receptor gamma (hPPAR gamma) gene in diabetic Caucasians: identification of a Pro12Ala PPAR gamma 2 missense mutation. Biochem. Biophys. Res. Commun. 241: 270-274. http://dx.doi.org/10.1006/bbrc.1997.7798

Zhang C, Bao W, Rong Y, Yang H, et al. (2013). Genetic variants and the risk of gestational diabetes mellitus: a systematic review. Hum. Reprod. Update 19: 376-390. http://dx.doi.org/10.1093/humupd/dmt013

Genetics and Molecular Research 15 (4): gmr15047682 